\title{
The effects of zinc deficiency on homeostasis of twelve minerals and trace elements in the serum, feces, urine and liver of rats
}

Qingli Yu ${ }^{1+}$, Xiaohan Sun ${ }^{2+}$, Jiali Zhao ${ }^{1}$, Lan Zhao ${ }^{3}$, Yanfeng Chen ${ }^{3}$, Lina Fan ${ }^{1}$, Zixiang Li ${ }^{1}$, Yongzhi Sun ${ }^{1}$, Maoqing Wang ${ }^{4^{*}}$ and Fan Wang ${ }^{5^{*}}$

\begin{abstract}
Background: Zinc deficiency can change the concentrations of minerals and trace elements in the body. However, previous studies still had many limitations.

Objective: To reveal the effects of zinc deficiency on homeostasis of 16 minerals and trace elements.

Methods: Forty-five rats were divided randomly into three groups: normal zinc diet ( $30 \mathrm{mg} / \mathrm{kg}$ ), low zinc diet (10 $\mathrm{mg} / \mathrm{kg})$, and pair-fed diet $(30 \mathrm{mg} / \mathrm{kg}$ ). The concentrations of 16 minerals and trace elements in serum, feces, urine, and liver were measured by inductively coupled plasma mass spectrometry. The excretion of 16 elements in urine and feces were calculated and compared.

Results: Zinc-deficient rats exhibited significant changes in up to 12 minerals and trace elements. The low zinc diet induced decreased excretion of zinc and concentrations of zinc in serum, feces, urine, and liver. Zinc deficiency increased feces concentrations of Mg, Cu, Se, K, Ag, Fe and Mn; decreased the concentrations of Mg, Cu, Se, K in liver and urine, and a diminished amount of Ag was observed in serum. Decreased urinary concentrations of Zn Ca, $\mathrm{Mg}, \mathrm{Cu}, \mathrm{Se}, \mathrm{K}, \mathrm{Na}$, As and $\mathrm{Cr}$, suggested that zinc-deficient rats increased the 9 elements' renal reabsorption. Decreased concentrations of Ca in liver, urine, and feces, decreased excretion in urine and feces and increased serum total Ca suggested that zinc deficiency increased the redistribution of Ca in serum or other tissues. Zinc deficiency increased excretion of $\mathrm{Cu}$, Se, Fe; and decreased the excretion of other 8 elements except for Ag.

Conclusions: Zinc deficiency changed the excretion, reabsorption and redistribution of 12 minerals and trace elements in rats. Our findings are the first to show that zinc deficiency alters the concentrations of $\mathrm{Ag}$, $\mathrm{Cr}$, and $\mathrm{As}$.
\end{abstract}

Keywords: Zinc deficiency, ICP-MS, Minerals, Trace elements, Rat

\footnotetext{
*Correspondence: wang_maoqing@126.com; yifan.701@163.com

${ }^{+}$Qingli Yu and Xiaohan Sun contributed equally to this work.

${ }^{4}$ National Key Disciplines of Nutrition and Food Hygiene, Department of Nutrition and Food Hygiene, School of Public Health, Harbin Medical University, 157 Baojian Road, Nangang District, Harbin, China

${ }^{5}$ Department of Epidemiology, School of Public Health, Harbin Medical

University, 157 Baojian Rd, Nangang District, Harbin, Heilongjiang Province,

People's Republic of China

Full list of author information is available at the end of the article
}

(c) The Author(s). 2019 Open Access This article is distributed under the terms of the Creative Commons Attribution 4.0 International License (http://creativecommons.org/licenses/by/4.0/), which permits unrestricted use, distribution, and reproduction in any medium, provided you give appropriate credit to the original author(s) and the source, provide a link to the Creative Commons license, and indicate if changes were made. The Creative Commons Public Domain Dedication waiver (http://creativecommons.org/publicdomain/zero/1.0/) applies to the data made available in this article, unless otherwise stated. 


\section{Introduction}

Zinc is an essential trace element in human body and plays extensive and important physiological functions [1, 2]. Left untreated, zinc deficiency can cause many adverse effects, including growth retardation, poor appetite, delayed sexual development, learning and memory disabilities, impaired immunity, and diabetes [1, 3-9]. Investigators have reported that zinc deficiency altered the concentrations of seven minerals and trace elements ( $\mathrm{Fe}$, $\mathrm{Mn}, \mathrm{Cu}, \mathrm{Mg}, \mathrm{Ca}, \mathrm{Na}$, and $\mathrm{K}$ ) in serum, urine, and tissues such as liver, bone, testes, muscle, esophagus, kidney, heart, brain, spleen, thyroid and adrenal glands, esophagus, and spleen [10-16]. In addition to zinc deficiency, abnormal concentrations of the above minerals and trace elements can also cause adverse physiological effects. For example, abnormal concentrations of iron areassociated with anemia and immunological disorders [17], manganese with nervous system diseases [18], copper with cardiovascular diseases and cancer $[19,20]$,calcium with BMD, magnesium and manganese with diabetes [3] and $\mathrm{Na}$ with hypertension. However, it is not clear whether zinc deficiency-induced alterations in the concentrations of these other elements are responsible for the foregoing adverse effects. Therefore, it is necessary to investigate the direct effects of zinc deficiency on the alterations of minerals and trace elements of body.

Existing studies about the effects of zinc deficiency on the alterations of minerals and trace elements in the body still have many limitations. First, to our knowledge, the concentrations of only two or three elements (usually $\mathrm{Cu}, \mathrm{Mg}$, and $\mathrm{Fe}$ ) were measured in most previous studies; in only two studies researchers have measured nine or more elements simultaneously in brain tissues [14] and serum [16]. Second, the concentrations of minerals and trace elements in human or animal feces have not been reported for conditions of zinc deficiency. Likewise, there is no study of zinc-deficient animals or humans for which measurements of minerals and trace elements have been performed concurrently in serum, urine, feces, and tissues. Lastly, in most studies, investigators have used atomic absorption spectroscopy (AAS) for quantitative analysis of minerals and traces elements. Compared with AAS, inductively coupled plasma mass spectrometry (ICP-MS) can quantify multiple elements simultaneously, and ICP-MS has been applied widely for that purpose.

In this study, we used ICP-MS to simultaneously measure the concentrations of 16 minerals and trace elements in multiple samples (serum, feces, urine, and liver) of rats fed a low-zinc diet and calculate their excretion in urine and feces. By analyzing intake, excretion, and redistribution, we comprehensively revealed the effects of zinc deficiency on homeostasis of these 16 elements.

\section{Method and materials}

\section{Animal experiment}

The study was approved by the Harbin Medical University Institutional Animal Care Committee and performed in accordance with the Harbin Medical University guidelines for the care and use of laboratory animals. Forty-five fiveweek-old male Wistar rats(110-130 g) were purchased from Beijing Vital River Laboratory Animal Technology Co., Ltd. They were maintained with a controlled light schedule (12 h light: $12 \mathrm{~h}$ dark) at room temperature (24 \pm $1{ }^{\circ} \mathrm{C}$ ) and with constant humidity $(50 \% \pm 5 \%)$. After an adaptation period of 7 days, the rats were randomly divided into three groups: normal zinc diet group, $n=15$, NZG; low zinc diet group, $\mathrm{n}=15$, LZG; and pair-fed group, $\mathrm{n}=15$, PZG. The animal diets were modified based on the standard AIN-93Gdiet with dried egg white as the protein source from Beijing KeAoLiXie Animal Food co., LTD, China. The contents of minerals and trace elements and compositions in the diets are detailed in Additional file 1: Table S1.The target content of zinc was 30 $\mathrm{mg} / \mathrm{kg}$ in the normal diet and $10 \mathrm{mg} / \mathrm{kg}$ in the low zinc diet. We used flame atomic absorption spectrometry to confirm the target zinc contents; the normal diet had 30.4 $\mathrm{mg} / \mathrm{kg}$ of zinc and the low zinc diet had $9.7 \mathrm{mg} / \mathrm{kg}$. The pair-fed zinc group (PZG) was fed a normal-zinc diet, and daily food intakes were same as in LZG. To avoid zinc recycling and contamination, the rats were housed singly in stainless steel cages. All rats were allowed to drink deionized water from a plastic container with a stainless-steel spray nozzle. Food intake was recorded every two days, and body weight was measured once a week.

\section{Sample collection, pretreatment and detection of serum biochemical indicators \\ Sample collection}

Before the end of the experiment, the animals were transferred to metabolic cages with a sharp bottom funnel to collect urine and feces samples. The $24 \mathrm{~h}$-urine and stools were collected twice. The volume of urine and weight of feces were recorded and the average of feces weight and urine volume was calculated and recorded. The feces of all rats were collected and placed in non-ionic EP tubes, and stored at $-80^{\circ} \mathrm{C}$. The urine of all rats was separated from feces by a sharp bottom funnel; and was collected in $15 \mathrm{ml}$ ion-free plastic centrifuge tubes (Corning Incorporated) and subjected to centrifugation at $3000 \mathrm{rpm}(835 \mathrm{~g})$ for $10 \mathrm{~min}$. The supernatants were stored at $-80^{\circ} \mathrm{C}$.After 4 weeks of feeding, all rats were fasted for $12 \mathrm{~h}$ and then anesthetized by intraperitoneal injection of $10 \%$ Chloral hydrate $(0.3 \mathrm{ml} / \mathrm{kg}$ body weight). Blood samples were collected from abdominal aorta and placed at room temperature for $2 \mathrm{~h}$. After centrifugation for $15 \mathrm{~min}$ at $3000 \mathrm{rpm}(835 \mathrm{~g})$, the separated serum was stored at $-80^{\circ} \mathrm{C}$. The livers were removed, 
washed several times with deionized water, then placed in $15 \mathrm{ml}$ ion-free plastic centrifuge tubes at $-80^{\circ} \mathrm{C}$.

\section{Measurements of serum biochemical indicators}

The concentrations of free zinc and free calcium in serum were measured by colorimetry (the reagent kits were purchased from Sigma-Aldrich, China), and the serum concentrations of metallothionein, growth hormone, interleukin (IL)-1, IL-6, thymosin, and insulin were measured by ELISA (kits from Summus, Harbin and Sigma-Aldrich).

Quantitative analysis of16 minerals and trace elements in serum, feces, urine, and liver of rats by ICP-MS

\section{Sample pretreatment}

All samples were pretreated by wet digestion. Serum $(200 \mu \mathrm{l})$ was placed in $50 \mathrm{ml}$ glass conical bottles cleaned by deionization. After adding $\mathrm{HNO}_{3}: \mathrm{HClO}_{4}(4: 1)$ solution (Guaranteed reagent, Xilong Scitenfic, China), the mixtures were digested in a temperature-controlled furnace at $100{ }^{\circ} \mathrm{C}$ until the solutions became colorless or complete. To reduce the concentration of acid in the digestive solution, $3 \mathrm{ml}$ deionized water was added and dried it twice by heated. The digested materials were dis-

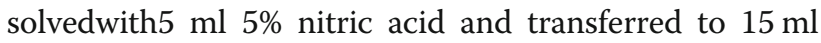
ion-free plastic centrifuge tubes.

The pretreatment methods of feces, urine, and liver were the same as that for serum. Specifically, $0.05 \mathrm{~g}$ of feces, $200 \mu \mathrm{l}$ of urine, and $0.1 \mathrm{~g}$ of liver were pretreated. The digested materials were dissolvedwith $5 \mathrm{ml} 5 \%$ nitric acid solution and transferred to a $15 \mathrm{ml}$ ion-free plastic centrifuge tube.

\section{Quantitative analysis of 16 minerals and trace elements by ICP-MS}

The concentrations of 16 minerals and trace elements in the samples were detected with an Agilent 7800 inductively coupled plasma-mass spectrometer (ICP-MS, Agilent) in the Heilongjiang Provincial Center for Disease Control and Prevention [21]. The parameters of ICP-MS were the following: radiofrequency $(\mathrm{RF})$ power: $1.55 \mathrm{~kW}$; sampling depth: $8 \mathrm{~mm}$; plasma gas flow: $15.0 \mathrm{~L} / \mathrm{min}$; carrier gas $(\mathrm{Ar}): 1.03 \mathrm{~L} / \mathrm{min}$; dilution gas, $0 \mathrm{~L} / \mathrm{min}$; auxiliary gas, $0.9 \mathrm{~L} / \mathrm{min}$; spray chamber temperature $(\mathrm{L}): 2{ }^{\circ} \mathrm{C}$; peristaltic pump: $0.10 \mathrm{r} / \mathrm{s}$. Helium mode was operated in high energy mode which offers enhanced sensitivity for selenium. Helium gas flow: $10 \mathrm{ml} / \mathrm{min}$ and KED was $4 \mathrm{~V}$.

A calibration standard solution (No:5183-4688) was purchased from Agilent Technology Co., Ltd. Calibration standards were prepared as follows: $10 \mathrm{mg} / \mathrm{L}$ mixed standard reserve solution was diluted with $5 \%$ nitric acid to produce mixed standard solution serials of various elements $(0.5,1,2,5$, and $10 \mathrm{mg} / \mathrm{L}$ for $\mathrm{K}, \mathrm{Ca}, \mathrm{Na}, \mathrm{Mg}$, and Fe and $5,10,20,50,100 \mu \mathrm{g} / \mathrm{L}$ for $\mathrm{Al}, \mathrm{Cr}, \mathrm{Mn}, \mathrm{Cu}, \mathrm{Zn}$, $\mathrm{As}, \mathrm{Se}, \mathrm{Ag}, \mathrm{Sn}, \mathrm{Ba}$, and $\mathrm{Pb}$ ). The standard curves were drawn with count per second (CPS) as ordinate and mass concentration as abscissa. The elemental contents in certified reference material (Trace Elements Serum L1 RUO, Seronorm ${ }^{\mathrm{Tm}}$ ) were determined by the established method for the determination of the elements in this study. The results confirmed the accuracy of our method.

\section{Statistical analysis}

Serum biochemical indicators and the concentrations of minerals and trace elements were expressed as mean \pm SD. Differences between the groups were analyzed by an independent $\mathrm{t}$ test and ANOVA test. A two-tailed value of $P<0.05$ was considered to be statistically significant. Data were analyzed using SPSS software (version 17.0, Chicago, IL, USA).

\section{Results}

The weights, food intake, and serum indicators of rats After 12 days of low zinc diet, the food intake of LZG was significantly lower than that of NZG $(P<0.01)$ (Fig. 1). From 21 to 28 days, the body weights of LZG were significantly lower than the weights of NZG and PZG $(P<0.05)$; and the body weights of PZG were
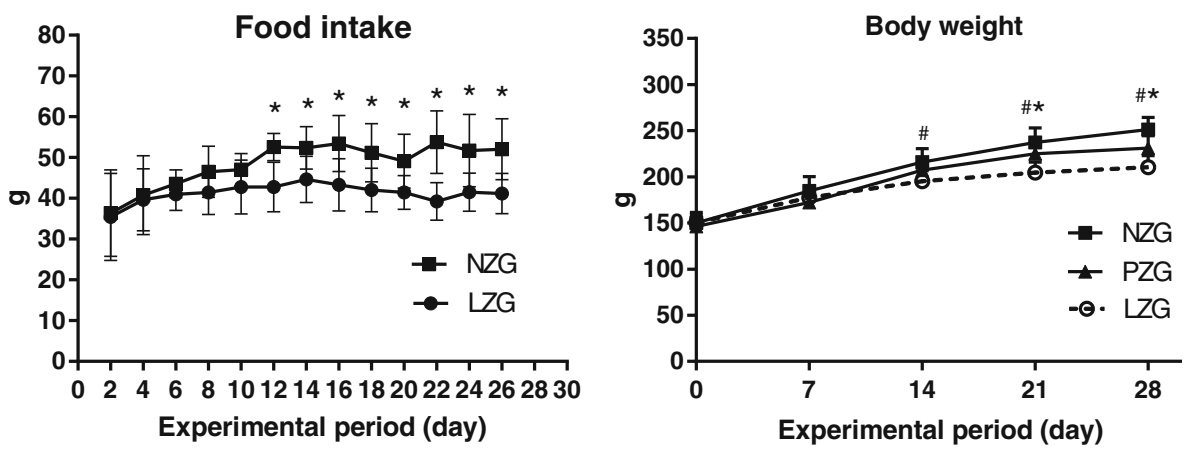

Fig. 1 Change trends in food intakes and body weight of three groups. *: $P<0.05$, LZG vs NZG; \#: $P<0.05$, LZG vs PZG 
significantly lower than the weights of NZG $(P<0.05)$ (Fig. 1).

As shown in Table 1, we observed significantly decreased serum concentrations of free zinc, metallothionein, growth hormone, interleukin (IL)-1/IL-6, thymosin, and insulin in LZG compared with NZG and PZG $(P<0.05)$. There were no significant statistical differences in all serum indicators between PZG and NZG. These findings confirmed that our zinc-deficient rat model was successfully established.

The concentrations of 16 minerals and trace elements in the serum, feces, urine and liver of rats

Serum minerals and trace elements

As shown in Fig. 2 and Additional file 1: Table S2, we found significantly decreased concentrations of total $\mathrm{Zn}$ and $\mathrm{Ag}$ in serum and significantly increased serum $\mathrm{Ca}$ in LZG compared with NZG and PZG $(P<0.05)$; we did not find significant differences for 13 other elements.

\section{Feces minerals and trace elements}

As shown in Fig. 3, Additional file 1: Figure S1 and Table S3, in feces, the concentrations of $\mathrm{Zn}$ and $\mathrm{Ca}$ were significantly decreased and the concentrations of $\mathrm{Mg}$, $\mathrm{Cu}, \mathrm{K}, \mathrm{Se}, \mathrm{Fe}, \mathrm{Mn}$, and $\mathrm{Ag}$ were significantly increased in LZG compared with NZG and PZG $(P<0.05)$; significant changes for 7 other elements were not observed.

\section{Urinary minerals and trace elements}

As shown in Fig. 3, Additional file 1: Figure S2 and Table S4, the concentrations of $\mathrm{Zn}, \mathrm{Ca}, \mathrm{Mg}, \mathrm{Cu}, \mathrm{Na}, \mathrm{K}$, $\mathrm{Se}, \mathrm{Cr}$, and $\mathrm{As}$ in urine were significantly decreased in LZG compared with NZG and PZG $(P<0.05)$; we did not find significant differences for 7 other elements.

\section{Liver minerals and trace elements}

As shown in Fig. 3, Additional file 1: Figure S3 and Table S5, the concentrations of $\mathrm{Zn}, \mathrm{Ca}, \mathrm{Mg}, \mathrm{Cu}, \mathrm{K}$, and Se in liver were significantly decreased in LZG compared with NZG and PZG (all $P<0.05$ ), whereas 10 other elements showed no

Table 1 Serum biochemical indicators between 3 groups

\begin{tabular}{llll}
\hline Indicators & NZG & PZG & LZG \\
\hline Zinc ion $(\mathrm{mg} / \mathrm{L})$ & $1.23 \pm 0.25$ & $1.10 \pm 0.29$ & $0.75 \pm 0.29^{*}$ \\
Calcium ion $(\mathrm{mg} / \mathrm{L})$ & $64.72 \pm 2.10$ & $64.42 \pm 3.73$ & $65.05 \pm 1.38$ \\
Metallothionein $(\mu \mathrm{g} / \mathrm{L})$ & $6.23 \pm 0.96$ & $6.11 \pm 0.89$ & $2.05 \pm 0.95^{*}$ \\
Growth hormone $(\mathrm{ng} / \mathrm{L})$ & $5.32 \pm 2.06$ & $5.43 \pm 2.25$ & $2.19 \pm 1.87^{*}$ \\
IL-1 (ng/L) & $19.91 \pm 6.28$ & $18.00 \pm 3.76$ & $12.74 \pm 1.69^{*}$ \\
IL-6 (ng/L) & $70.96 \pm 25.90$ & $78.60 \pm 31.42$ & $32.26 \pm 10.11^{*}$ \\
Thymosin (mg/ml) & $2.89 \pm 0.54$ & $2.69 \pm 0.78$ & $0.67 \pm 0.46^{*}$ \\
Insulin (ng/ml) & $0.63 \pm 0.15$ & $0.62 \pm 0.17$ & $0.42 \pm 0.07^{*}$ \\
\hline *: $P<0.05 \mathrm{LZG} \mathrm{vs} \mathrm{NZG} \mathrm{and} \mathrm{PZG}$ & &
\end{tabular}

*: $P<0.05$ LZG vs NZG and PZG significant changes. The concentrations of 16 minerals and trace elements in the livers of PZG were not detected by us.

\section{Excretion of 12 minerals and trace elements in urine and feces}

As shown in Additional file 1: Figure S4, the weight of feces was significantly decreased in LZG compared with NZG and PZG $(P<0.05)$. The volume of urine in LZG suggested a decreasing trend, but the data were not statistically different between the groups. As shown in Fig. 4 and Additional file 1: Table S6, increased excretion of $\mathrm{Mg}, \mathrm{Cu}, \mathrm{Se}, \mathrm{K}, \mathrm{Fe}$ and decreased excretion $\mathrm{Zn}, \mathrm{Ca}, \mathrm{Na}, \mathrm{Cr}$ were observed in the feces LZG. For reduced urine concentrations and urine volume, urinary excretion of 12 elements was all decreased in LZG or their urinary reabsorption were increased.

Figure 4 and Additional file 1: Table S7 showed that the excretion of $\mathrm{Cu}$, Se and $\mathrm{Fe}$ in feces were greater than the reabsorption in urine. So, the total excretion of $\mathrm{Cu}, \mathrm{Se}$ and $\mathrm{Fe}$ were increased and zinc deficient rats lost $\mathrm{Cu}, \mathrm{Se}$ and $\mathrm{Fe}$. In contrast, the excretion of $\mathrm{Mg}$ and $\mathrm{K}$ in feces was less than the reabsorption in urine, so the total excretion of $\mathrm{Mg}$ and $\mathrm{K}$ were decreased and zinc deficient rats did not lose $\mathrm{Mg}$ and $\mathrm{K}$. Except for Ag, zinc deficiency increased the total excretion of $\mathrm{Cu}$, Se and $\mathrm{Fe}$, while the results of other 8 elements were opposite.

\section{Discussion}

We have used ICP-MS to concurrently measure the concentrations of 16 minerals and trace elements in serum, feces, urine, and liver of zinc-deficient rats. Compared to normal diet rats, low zinc diet caused changes in the levels of 12 minerals and trace elements.

\section{The alterations of 12 differential minerals and trace elements in four samples}

Previous studies have indicated that the serum concentrations of $\mathrm{Zn}, \mathrm{Mn}, \mathrm{Cu}, \mathrm{Mg}$, Se, and Fe were changed by a zinc-deficient diet $[11,16]$. We found decreased $\mathrm{Zn}$ and $\mathrm{Ag}$ and increased Cain serum of LZG compared with NZG (Fig. 3). The concentrations of $\mathrm{Mn}$ and $\mathrm{Cu}$ suggested a decreasing trend, but the data were not statistically different between the groups. The main reason why our test results are inconsistent with other studies were that the zinc content $(\leq 5 \mathrm{mg} / \mathrm{kg}$ ) in the low zinc diets of other studies was less than our low zinc $\operatorname{diet}(10$ $\mathrm{mg} / \mathrm{kg}$ ), and rats were maintained on low zinc diets for longer periods than in our study. Furthermore, other investigators measured only free elements in serum, except the elements bound to proteins. Conversely, in our study, we measured the total levels of 16 elements in serum, including free elements and elements bound to serum proteins.

In liver, the concentrations of $\mathrm{Zn}, \mathrm{Ca}, \mathrm{Mg}, \mathrm{Cu}, \mathrm{K}$ and $\mathrm{Se}$ were significantly decreased in LZG compared with NZG (Fig. 3); these changes were consistent with other reports $[10$, 

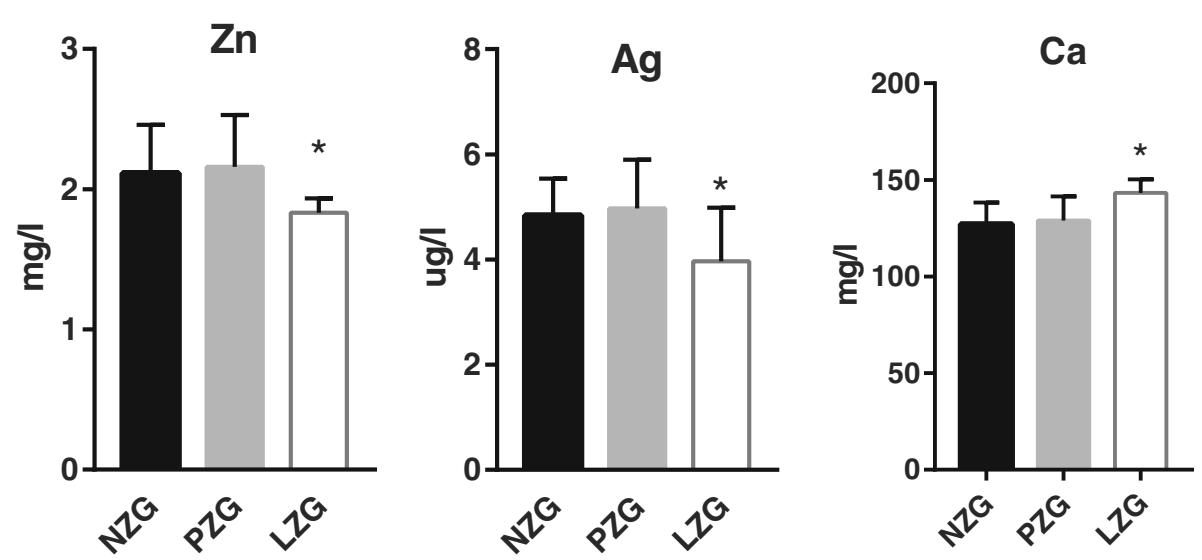

Fig. 2 Concentrations of three minerals and trace elements in serum between three groups. *: $P<0.05$ LZG vs NZG and PZG

22-24]. Notably, for the first time, our results indicated that zinc deficiency caused a decrease in the concentrations of liver Se. Compared to NZG, the significantly decreased urinary $\mathrm{Cu}, \mathrm{Se}, \mathrm{K}, \mathrm{Na}, \mathrm{As}$ and $\mathrm{Cr}$ except for $\mathrm{Zn}, \mathrm{Mg}$ and $\mathrm{Ca}$ in zinc deficient rats were first observed in our study (Fig. 3). Marginal zinc deficiency can reduce the excretion of $\mathrm{Mg}$ and $\mathrm{Ca}$ into urine and increase their retention [13],observations that are consistent with our findings. In feces, we found for the first time that zinc deficiency induced alterations in the concentrations of nine elements, i.e., increased $\mathrm{Mg}, \mathrm{Cu}, \mathrm{Se}$, $\mathrm{K}, \mathrm{Ag}, \mathrm{Fe}$, and $\mathrm{Mn}$, and decreased $\mathrm{Zn}$ and $\mathrm{Ca}$.

In sum, we found that zinc deficiency induced alterations in the concentrationsof 12 minerals and trace elements in rats, including previously unreported alterations in $\mathrm{Ag}$, As, and $\mathrm{Cr}$ (Figs. 3 and 4).

Reasons for alterations of twelve differential minerals and trace elements

Effects of food intake and body weight on the levels of 12 minerals and trace elements

In our study, the food intake of PZG was significantly lower than that of NZG. The intakes of minerals and trace elements in PZG were significantly reduced compared with NZG, and the concentrations of minerals and trace elements in PZG should be reduced. However, the body weights of PZG were significantly lower than the weights of NZG $(P<0.05)$ (Fig. 1). We speculate that decreased body weights may reduce the consumption of minerals and trace elements and maintain their normal levels in the body when the zinc status of rats is normal. Therefore, there were no significant differences in the concentrations of 12 elements in serum, feces, urine, and liver between these two normal zinc diet groups (PZG and NZG).

The PZG group was fed a normal-zinc diet, and their daily food intakes were the same as in LZG. So, the intakes of other minerals and trace elements except for Zinc in PZG were as same as in LZG. The result indicated that food intake had no effect on the concentrations of 12 elements. Compared with PZG, the body weights and feces weights of LZG were significantly decreased. Reduced body and weight feces weights may reduce the consumption and excretion of minerals and trace elements and tried to maintain their level in the body. However, when rats were in a zinc-deficient state,

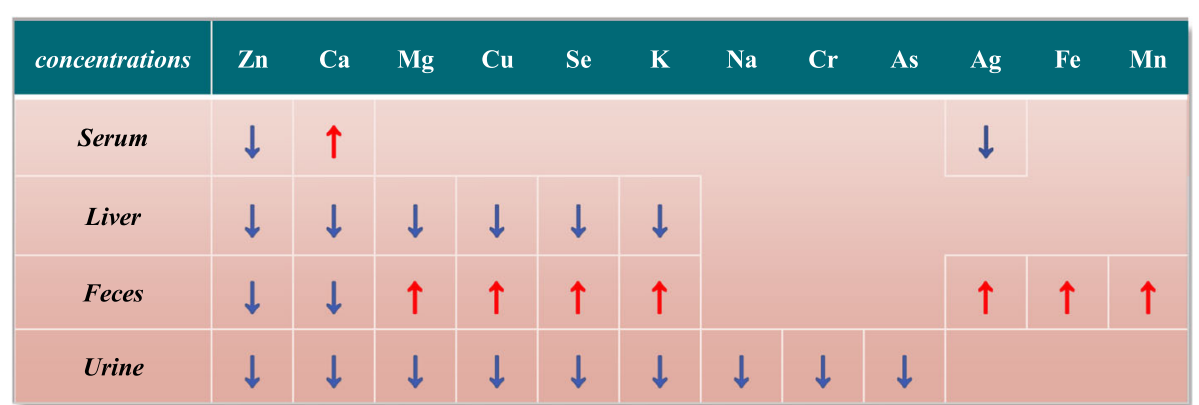

Fig. 3 Trend analysis of concentration change of twelve minerals and trace elements in serum, feces, urine and liver between three groups. *: $P<$ 0.05 LZG vs NZG and PZG. The red arrow represents a significant increase: $\uparrow, L Z G$ vs. NZG; the blue arrow represents a significant decrease: $\downarrow, L Z G$ vs. NZG. Gray: first found in zinc deficient rats 


\begin{tabular}{|c|c|c|c|c|c|c|c|c|c|c|c|c|c|}
\hline excretions & $\mathrm{Zn}$ & $\mathrm{Ca}$ & $\mathrm{Mg}$ & $\mathrm{Cu}$ & $\mathrm{Se}$ & $\mathrm{K}$ & $\mathrm{Na}$ & $\mathrm{Cr}$ & As & Ag & $\mathrm{Fe}$ & $\mathrm{Mn}$ \\
\hline Feces & $\downarrow$ & $\downarrow$ & $\uparrow$ & $\uparrow$ & $\uparrow$ & $\uparrow$ & $\downarrow$ & $\downarrow$ & & & $\uparrow$ & \\
\hline Urine & $\downarrow$ & $\downarrow$ & $\downarrow$ & $\downarrow$ & $\downarrow$ & $\downarrow$ & $\downarrow$ & $\downarrow$ & $\downarrow$ & $\downarrow$ & $\downarrow$ & $\downarrow$ \\
\hline Total & $\downarrow$ & $\downarrow$ & $\downarrow$ & $\uparrow$ & $\uparrow$ & $\downarrow$ & $\downarrow$ & $\downarrow$ & $\downarrow$ & & $\uparrow$ & $\downarrow$ \\
\hline
\end{tabular}

Fig. 4 Excretions of twelve minerals and trace elements by feces and urine. The red arrow represents a significant increase: $\uparrow, L Z G$ vs. NZG; the blue arrow represents a significant decrease: $\downarrow$, LZG vs. NZG

the reduced body weight was not sufficient to maintain the normal levels of the body's minerals and trace elements. And, the low-zinc diet eventually led to changes in 12 minerals and trace elements. The above results indicated that the alterations of 12 minerals and trace elements in LZG were induced by low zinc diet (or zinc deficiency), and were not related to food intake.

\section{Effects of dietary zinc content on the levels of $\mathrm{Zn}$ in body} Compared with the normal zinc diet groups (NZG and PZG), for the LZG group, we observed significant decreases in free serum zinc, total zinc in serum, feces, urine, and liver. Therefore, reduced dietary zinc content was the main cause of decreased zinc in the body [25]. To maintain zinc homeostasis, the zinc-deficient rats increased zinc reabsorption, thereby causing decreased concentrations of zinc in feces and urine and decreased excretion via urine and feces (Fig. 4). However, decreased excretion of fecal and urinary zinc was insufficient to meet the zinc demands of serum and liver, so eventually there were decreased concentrations of zinc in these samples.

\section{Effect of low-zinc diet on excretion and reabsorption of 10 minerals and trace elements}

Excretion and reabsorption of $\mathrm{mg}$, $\mathrm{cu}$, se, $\mathrm{K}$, ag, Fe and $\mathrm{Mn}$ by feces The concentrations and excretion of $\mathrm{Mg}, \mathrm{Cu}$, Se and $\mathrm{K}$ in feces of LZG were all significantly increased compared to NZG, whereas their concentrations in urine and liver were decreased (Fig. 4). These results suggested that zinc deficiency caused increased fecal excretion of these four elements. To maintain the concentrations of these four elements in the body, their urinary excretion was remarkably reduced. But homeostasis still could not be maintained, which led to a further decrease concentration of these four elements in liver. Increased total excretion of $\mathrm{Cu}$ and Se suggested that the serum concentrations of $\mathrm{Cu}$ and Se may also decline if zinc deficiency was further aggravated.
In contrast, the concentrations of $\mathrm{Ag}, \mathrm{Fe}$ and $\mathrm{Mn}$ in feces were significantly increased in LZG compared with NZG. However, feces excretion of Ag, Fe and Mn were not changed and decreased urinary excretion of $\mathrm{Ag}$ and Mn were observed in LZG. So, concentrations of Mn were unchanged in serum, urine and liver. But, lower Mn excretion did not decrease the serum concentration of $\mathrm{Mn}$ in LZG. In serum, the concentration of $\mathrm{Ag}$ was decreased significantly due to feces excretion, whereas Fe only showed a decreasing trend. And further exacerbation of zinc deficiency may decrease the concentration of serum Fe for higher feces excretion. Brad J. Niles reported that zinc deficiency induced a consequence of alterations in iron regulatory protein-binding activity, iron transporters, and iron storage protein [26].

Increased excretion of $\mathrm{Cu}, \mathrm{Se}$ and $\mathrm{Fe}$ suggested that zinc deficient rats were at risk of $\mathrm{Cu}, \mathrm{Se}$ and $\mathrm{Fe}$ deficiency.

Excretion and reabsorption of $\mathrm{Na}, \mathrm{Cr}$, and as by urine Compared with the NZG, the concentrations of $\mathrm{Na}$, As, and $\mathrm{Cr}$ in urine of LZG and their excretion were significantly decreased; however, their concentrations were normal in serum, feces, and liver (Figs. 3 and 4). Others have reported that the concentrations of $\mathrm{Na}$ and $\mathrm{K}$ in cerebellum and hippocampus of zinc-deficient rats were higher than those of normal rats [14]. The decreased $\mathrm{K}$ excretion of LZG was also observed in our study. We speculate that the urinary reabsorption of $\mathrm{Na}$ and $\mathrm{K}$ in zinc-deficient rats was increased to maintain high concentrations of $\mathrm{Na}$ and $\mathrm{K}$ in other tissues; this resorption, in turn, caused diminished urinary excretion of $\mathrm{Na}$ and $\mathrm{K}$. To verify this hypothesis, it is necessary to measure concentrations of $\mathrm{Na}$ and $\mathrm{K}$ in other tissues.

\section{Effect of low-zinc diet on the redistribution of ca}

We did not find a significant difference in dietary calcium intake between LZG and PZG (Fig. 1). However, the concentrations of $\mathrm{Ca}$ in liver, feces, and urine and excretion of $\mathrm{Ca}$ in feces and urine of LZG were 
remarkably decreased compared with PZG and NZG (Figs. 3 and 4). These results suggested that zinc deficiency increased the reabsorption of calcium by decreasing calcium excretion, so that the calcium of LZG rats was not lost. But where did the decreased calcium go in the LZG rats? In our study, using colorimetry, we did not detect a significant difference in the level of free calcium $\left(\mathrm{Ca}^{2+}\right)$ in serum between LZG and NZG (Table 1). However, the total amount of calcium in LZG serum was significantly increased compared with NZG and PZG (Fig. 2). Total calcium in serum includes free calcium (calcium ion), protein-bound calcium, and other calcium compounds. The absence of a change in free serum calcium suggested that the level of protein-bound calcium or calcium compounds was increased. We speculate that zinc deficiency may increase the distribution of calcium in serum or other tissues and decrease calcium excretion. The possible mechanism is due to the antagonism of zinc and calcium by calcium-activated calmodulin [27, 28]. Zinc is an inhibitor both of calcium-activated calmodulin. $\mathrm{Zn}$ deficiency raised the Ca concentration in the brain, muscle, testis by elevated calmodulin concentration $[29,30]$.

\section{Adverse effects of alterations in minerals and trace elements}

Minerals and trace elements are widely distributed in the body and have important physiological functions. Abnormal availability of minerals and trace elements induces serious adverse effects [19, 31-33].

Decreases in body weight, growth hormone, dietary intake, thymic organ coefficient, IL-1/IL-6, thymosin, and insulin in LZG indicated that zinc deficiency negatively affected growth, immunity, and sugar metabolism in rats (Table 1). It is well known that zinc deficiency is related to growth retardation [34], impaired immunity function [5], and emergence of diabetes [3, 9]. In contrast to zinc deficiency that affects these three aspects of physiology, impaired growth and development is associated with magnesium deficiency [35], selenium, iron, and magnesium deficiencies are related to impaired immune function [32, 36-40], and copper, magnesium, and manganese have important functions in regulation of blood sugar [3, 41]. Therefore, in addition to the direct adverse effects induced by zinc deficiency, changes in other minerals and trace elements induced by zinc deficiency may also indirectly promote the above adverse effects. In addition, iron deficiency can cause anemia [17], copper deficiency affects the occurrence and development of cardiovascular diseases $[19,20]$, and magnesium and calcium deficiencies are linked to osteoporosis [42]. Recent literature has confirmed that zinc deficiency is closely related to decreased BMD and osteoporosis [4345]. We hypothesize that the redistribution of calcium in the body induced by zinc deficiency played an important role in decreased BMD and osteoporosis. Therefore, our results suggest that the alterations of minerals and trace elements induced by zinc deficiency may be associated with the above adverse effects.

\section{Conclusion}

Our results confirmed that zinc deficiency induced alterations in the concentrations of 12 minerals and trace elements in serum, urine, feces and liver of rats. These changes occurred by increased excretion of $\mathrm{Cu}$, Se and Fe, decreased excretion of 8 elements, and increased redistribution of calcium in serum or other tissues.

\section{Supplementary information}

Supplementary information accompanies this paper at https://doi.org/10. 1186/s12986-019-0395-y.

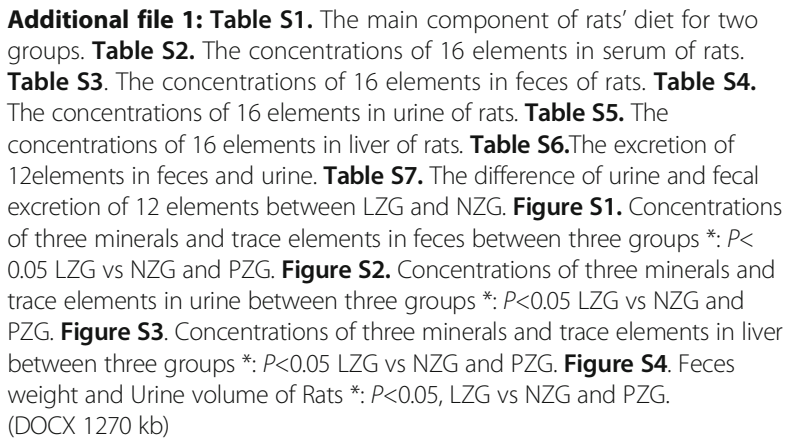

\section{Abbreviations}

AAS: Atomic absorption spectroscopy; BMD: Bone mineral density; CPS: Count per second; ICP-MS: Inductively coupled plasma mass spectrometry; LZG: Low zinc diet group; NZG: Normal zinc diet group; PZG: Pair-fed group; RF: Radiofrequency

\section{Acknowledgements}

The authors would like to thank AiMi (www.aimieditor.com) for providing linguistic assistance.

\section{Authors' contributions}

Maoqing Wang and Fan Wang contributed to the study's conception and design. QingliYu and Xiaohan Sun contributed to drafting of the manuscript. QingliYu, Zixiang Li and Yongzhi Sun performed animal experiments and data collection. Lan Zhao and Yanfeng Chen measured element concentrations by ICP-MS. Jiali Zhao and Lina Fan performed data analysis and interpretation. The final draft was read and approved by all the authors.

\section{Funding}

This work was supported by grants from National Nature Science Foundation of China (81573147)

\section{Availability of data and materials}

The datasets used and/or analyzed during the current study are available from the corresponding author on reasonable request.

\section{Ethics approval}

This animal study was performed according to institutional guidelines with the approval of the Institutional Animal Care and Use Committee of the Harbin Medical University. 


\section{Consent for publication}

Not applicable.

\section{Competing interests}

All authors have declared that no conflict of interest exists.

\section{Author details}

'National Key Disciplines of Nutrition and Food Hygiene, Department of Nutrition and Food Hygiene, School of Public Health, Harbin Medical University, 157 Baojian Road,Nanggang District, Harbin, China. ${ }^{2}$ Department of Pediatrics, The Second Affiliated Hospital of Harbin Medical University, Harbin Medical University, Harbin, Heilongjiang Province, China. ${ }^{3}$ Public Health Inspection and Testing Institute, Heilongjiang Provincial Center for Disease Control and Prevention, Harbin, China. ${ }^{4}$ National Key Disciplines of Nutrition and Food Hygiene, Department of Nutrition and Food Hygiene, School of Public Health, Harbin Medical University, 157 Baojian Road, Nangang District, Harbin, China. ${ }^{5}$ Department of Epidemiology, School of Public Health, Harbin Medical University, 157 Baojian Rd, Nangang District, Harbin, Heilongjiang Province, People's Republic of China.

\section{Received: 27 May 2019 Accepted: 6 September 2019}

\section{Published online: 30 October 2019}

\section{References}

1. Prasad AS. Impact of the discovery of human zinc deficiency on health. J Trace Elem Med Biol. 2014;28:357-63.

2. Hambidge KM, Krebs NF. Zinc deficiency: a special challenge. Journal of Nutrition2007; 137:1101-1105.

3. Jr WR, Uriu-Hare JY, Olin KL, Oster MH, Anawalt BD, Critchfield JW, Keen CL. Copper, zinc, manganese, and magnesium status and complications of diabetes mellitus. Diab Care. 1991;14:1050.

4. Halas ES, Hunt CD, Eberhardt MJ. Learning and memory disabilities in young adult rats from mildly zinc deficient dams. Physiology Behavior. 1986:37:451-8.

5. Maares M, Haase H. Zinc and immunity: an essential interrelation. Arch Biochem Biophys. 2016;611:58-65.

6. Uriu-Adams JY, Keen CL. Zinc and reproduction: effects of zinc deficiency on prenatal and early postnatal development. Birth Defects Res B Dev Reprod Toxicol. 2010;89:313-25

7. Wong CP, Magnusson KR, Ho E. Increased inflammatory response in aged mice is associated with age-related zinc deficiency and zinc transporter dysregulation. J Nutr Biochem. 2013;24:353-9.

8. Wong CP, Rinaldi NA, Ho E. Zinc deficiency enhanced inflammatory response by increasing immune cell activation and inducing IL6 promoter demethylation. Mol Nutr Food Res. 2015:59:991-9.

9. Jansen J, Karges W, Rink L. Zinc and diabetes - clinical links and molecular mechanisms. J Nutr Biochem. 2009;20:399-417.

10. Zhao $\mathrm{C}$, Yang $\mathrm{H}$, Jiang $\mathrm{H}$. Effects of zinc deficiency on the distribution of elements in the tissue of pregnant rats and their fetuses. J Hygiene Res 2001; 30:277

11. El HHA, Yousef Ml, Abo E-NNI. Effect of dietary zinc deficiency on hematological and biochemical parameters and concentrations of zinc, copper, and iron in growing rats. Toxicology. 2001;167:163-70.

12. Niles BJ, Clegg MS, Hanna LA, Chou SS, Momma TY, Hong H, Keen CL. Zinc deficiency-induced iron accumulation, a consequence of alterations in iron regulatory protein-binding activity, iron transporters, and iron storage proteins. J Biol Chem. 2008;283:5168-77.

13. Nielsen FH. Marginal zinc deficiency increases magnesium retention and impairs calcium utilization in rats. Biol Trace Elem Res. 2009;128:220.

14. Wallwork JC, Milne DB, Sims RL, Sandstead HH. Severe zinc deficiency: effects on the distribution of nine elements (potassium, phosphorus, sodium, magnesium, calcium, iron, zinc, copper and manganese) in regions of the rat brain. J Nutr. 1983;113:1895-905.

15. Prasad AS, Oberleas D, Wolf P, Horwitz JP, Collins R, Vazquez JM. Studies on zinc deficiency: changes in trace elements and enzyme activities in tissues of zinc-deficient rats. J Clin Invest. 1967:46:549-57.

16. Xiao-Dan YU, Yan C-H, Xiao-Gang YU. Effect of zinc deficiency on serum elements in growing rats. Studies of trace elements and Health. 2009;26(6)

17. Lieu PT, Heiskala M, Peterson PA, Yang Y. The roles of iron in health and disease. Mol Aspects Med. 2001;22:1-87.

18. Takeda A. Manganese action in brain function. Brain Res Brain Res Rev. 2003:41:79-87.
19. Kang YJ. Copper and homocysteine in cardiovascular diseases. Pharmacol Ther 2011; 129:321-331.

20. Cartwright GE, Wintrobe MM. The question of copper deficiency in man. Am J Clin Nutr 1964; 15:94

21. Filipiak-Szok A, Kurzawa M, Szłyk E. Determination of toxic metals by ICP-MS in Asiatic and European medicinal plants and dietary supplements. J Trace Elem Med Biol. 2015;30:54-8.

22. Sun JY, Jing MY, Weng XY, Fu LJ, Xu ZR, Zi NT, Wang JF. Effects of dietary zinc levels on the activities of enzymes, weights of organs, and the concentrations of zinc and copper in growing rats. Biol Trace Elem Res. 2005;107:153-65.

23. Cho YE, Lomeda RA, Ryu SH, Sohn HY, Shin HI, Beattie JH, Kwun IS. Zinc deficiency negatively affects alkaline phosphatase and the concentration of ca, $\mathrm{mg}$ and $\mathrm{P}$ in rats. Nutr Res Pract. 2007:1:113-9.

24. Gupta RP, Verma PC, Sadana JR, Gupta VK. Effect of experimental zinc deficiency and repletion on sodium, potassium, copper and iron concentrations in Guinea-pigs. Br J Nutr. 1989;62:407-14.

25. Awotiwon AA, Oduwole $\mathrm{O}$, Sinha A, Okwundu Cl. Zinc supplementation for the treatment of measles in children. Cochrane Database Syst Rev. 2015;3: CD011177.

26. Niles BJ, Clegg MS, Hanna LA, Chou SS, Momma TY, Hong H, Keen CL. Zinc deficiency-induced Iron accumulation, a consequence of alterations in Iron regulatory protein-binding activity, Iron transporters, and Iron storage proteins. J Biol Chem. 2008;283:5168-77

27. Brewer GJ, Aster JC, Knutsen CA, Kruckeberg WC. Zinc inhibition of calmodulin: a proposed molecular mechanism of zinc action on cellular functions. Am J Hematol2010; 7:53-60.

28. O'Dell BL. Role of zinc in plasma membrane function. Journal of Nutrition2000. 130:1432S.

29. Hurley LS, Keen CL, Bo L, Rucker RB. Trace Elements in Man and Animals. 1988;6.

30. Roth HP, Kirchgessner M. Calmodulin, zinc and calcium concentration in tissues of zinc- and calcium-deficient rats. J Trace Elem Electrolytes Health Dis. 1988:2:73.

31. Sojka JE, Weaver CM. Magnesium supplementation and osteoporosis. Nutrition Rev. 2010;53:71-4.

32. Brock JH, Mainou-Fowler T. Iron and immunity. Proc Nutr Soc. 1993;45:305-15.

33. Yao Y, Pei F, Kang P. Selenium, iodine, and the relation with Kashin-Beck disease. Nutrition. 2011;27:1095-100.

34. Salqueiro MJ, Zubillaga MB, Lysionek AE, Caro RA, Weill R, Boccio JR. The role of zinc in the growth and development of children. Nutrition. 2002;18: 510-9.

35. Dees WL, Hiney JK, Srivastava VK. Influences of manganese on pubertal development. J Endocrinol 2017:JOE-17-0237.

36. Zhi H, Rose $\mathrm{AH}$, Hoffmann PR. The role of selenium in inflammation and immunity: from molecular mechanisms to therapeutic opportunities. Antioxid Redox Signal. 2012;16:705-43.

37. Taylor EW. Selenium and cellular immunity. Evidence that selenoproteins may be encoded in the +1 reading frame overlapping the human CD4, CD8, and HLA-DR genes. Biol Trace Elem Res. 1995;49:85.

38. Cassat JE, Skaar EP. Iron in infection and immunity. Cell Host Microbe 2013: 13:509-519.

39. Oppenheimer SJ. Iron and its relation to immunity and infectious disease. J Nutr. 2001:131:616S

40. Tam M, Gómez S, Gonzálezgross M, Marcos A. Possible roles of magnesium on the immune system. Eur J Clin Nutr. 2003:57:1193-7.

41. Zheng Y, Li XK, Wang Y, Cai L. The role of zinc, copper and iron in the pathogenesis of diabetes and diabetic complications: therapeutic effects by chelators. Hemoglobin. 2008;32:135-45

42. Sara C, Alessandra C, Walter A, Maier JAM. Magnesium and osteoporosis: current state of knowledge and future research directions. Nutrients. 2013;5:3022-33.

43. Yamaguchi M. Role of nutritional zinc in the prevention of osteoporosis. Mol Cell Biol. 2010:338:241-54.

44. Rico H, Villa LF. Zinc, a new coherent therapy for osteoporosis? Calcif Tissue Int 2000:67:422-3.

45. Hyun TH, Elizabeth B-C, MD B. Zinc intakes and plasma concentrations in men with osteoporosis: the rancho Bernardo study. Am J Clin Nutr. 2004:80: $715-21$

\section{Publisher's Note}

Springer Nature remains neutral with regard to jurisdictional claims in published maps and institutional affiliations. 